\title{
Editorial
}

\section{Uroginecología: pasado, presente y futuro}

Junto con una mayor expectativa de vida de mujeres y hombres, van surgiendo múltiples problemas que afectan su calidad de vida, es así como patologías del piso pélvico, se van transformando en una verdadera epidemia, con una alta prevalencia de enfermedades como la incontinencia de orina y prolapso genital, el área de la medicina responsable de enfrentar estas patologías corresponde a la Uroginecología.

La historia clínica de la uroginecología va de la mano con el desarrollo de la medicina, vale mencionar que el uso de pesarios para el manejo del prolapso genital data de 2000 años AC. La era moderna de esta especialidad comienza en 1849, cuando Marion Sims, un cirujano de Alabama y fundador del Hospital de Mujeres de Nueva York, exitosamente cerró una fistula vesico-vaginal en una esclava negra en su décimo tercer intento. En 1893, Howard Kelly, Profesor de Ginecología del Hospital Johns Hopkins, estudió problemas urológicos en mujeres, inventó el cistoscopio de aire y describió su técnica clásica para el tratamiento de la incontinencia de orina por vía vaginal. Desde esa fecha en adelante, muchos hitos han marcado el desarrollo de esta área de la ginecología y urología, como la gestación de la urodinamia moderna por Goren Enhorning en 1961, la descripción de múltiples técnicas quirúrgicas para la corrección de la incontinencia de orina (Burch, Mashall-Marchetti-Krantz, TVT, TOT, entre otras) y para la corrección de prolapso genital (colpocleisis, fijación a sacroespinoso y uterosacro alto, sacrocolpopexia, etc).

En 1974, dado el creciente interés de esta área multidisciplinaria se crea la International Continence Society (ICS), que reúne a especialistas en Urología, Coloproctología, Ginecología, Geriatría, y Kinesiólogos, todos reunidos para estudiar y dar solución a problemas del piso pélvico. En la medida que avanza el interés y conocimientos de las patologías que afectan el piso pélvico, proliferan sociedades científicas internacionales como la International Urogynecological Associatio (IUGA) y regionales, así mismo se desarrollan revistas de interés en ésta área y múltiples cursos anuales en diferentes partes del mundo.

El desarrollo de la Uroginecología en nuestro país se inicia como proyectos aislados en diferentes Hospitales, que ven en nuevas técnicas para la corrección de la incontinencia de orina y el prolapso genital, un atractivo polo de desarrollo. Estas incursiones aisladas se agrupan el año 2006, con la creación de la Sociedad Chilena de Uroginecología y Piso Pélvico (SODUP), que se ha caracterizado por ser una sociedad multidisciplinaria, e inclusiva que abarca Kinesiologos, Ginecólogos, Coloproctólogos y Urólogos, y fuertemente influenciada por un espíritu académico. Al poco andar se organiza un simposio regional de la IUGA en Chile el 2011, y múltiples instancias de desarrollo de ésta área de la medicina como cursos, diplomados y más recientemente programas de formación.

La creciente demanda por tratamientos efectivos para problemas del piso pélvico que afectan la calidad de vida de nuestros pacientes, ha llevado a la creación de múltiples programas de formación en esta área tanto en urología como en ginecología. A la fecha se cuentan más de 50 programas de formación reconocidos por la IUGA. La creación de estos programas de formación en Uroginecología y Cirugía Reconstructiva del Piso Pélvico, reconoce que el nivel de complejidad alcanzado por esta área de la medicina, trasunta especialidades como Ginecología y Urología. Son múltiples los nuevos test diagnósticos, procedimientos y técnicas quirúrgicas desarrolladas, que se escapan de la malla curricular de las especialidades madres. En la actualidad en Chile reconocemos programas de formación en uroginecología en la Universidades de Chile, Católica, Desarrollo y Valparaíso. Y dentro de la SODUP se está trabajando en criterios que den un piso de requisitos básicos para que estos programas estén a la par de programas en USA, Canadá, Europa y Australia. 
Contamos en nuestro país con un número creciente de médicos formados tanto en Chile como en el extranjero, que han incorporado una visión más global de esta especialidad y juegan un papel fundamental en la formación de alumnos de quintoaño de medicina, internos y residentes tanto de Urología como Ginecología y Obstetricia.

Si miramos al futuro de la Uroginecología, especialmente en nuestro país, creo debemos apuntar a la consolidación de centros de alta complejidad, capaces de lidiar con pacientes que presentan recidivas y/o complicaciones de cirugías o procedimientos, siempre relacionados a instituciones universitarias, capaces de formar urólogos o ginecólogos expertos en piso pélvico, y que promuevan investigación de buena calidad. Todo esto con el sentido de tener una masa crítica de médicos capaces de lidiar con patologías del piso pélvico, críticos ante la aparición de nuevas técnicas y/o procedimientos, y con el foco bien puesto en el bienestar de nuestros pacientes. Si logramos esta tarea estaremos en buen pie para el reconocimiento de la sub-especialidad en Uroginecología y Cirugía Reconstructiva del Piso Pélvico, una anhelada meta tanto dentro de la SODUP como en los diversos centros formadores.

\section{Bibliografía}

1- Contreras-Ortiz, O. Editorial. IUJ 1990 Vol 1, (1): 1-2

2- Kelly HA. Medical Gynecology. D. Apppleton and Co., New York, 1908

3- Ricci JV. The Geneology of Gynecology: History of the Development of Gynecology Throughout the Ages. The Blatkinston Company, Philadelphia, 1972.

Dr. Victor Miranda H., MSc

Profesor Asistente

Unidad de Uroginecología

División de Obstetricia y Ginecología

Escuela de Medicina

Pontificia Universidad Católica de Chile 